\title{
Derin Boyun Apsesi ve Peritoneal Sepsis Birlikteliği: Nadir Bir Ölüm Olgusu
}

\author{
Deep Neck Infection Associated with Peritoneal Sepsis: A Rare Death Case
}

\author{
Sait Özsoy ${ }^{l}$, Asude Gökmen², Mehtap Yöndem², Illker Sücüllü̈, Semra Duran ${ }^{4}$, Gulnaz Tatlıcı Javan \\ ${ }^{I}$ GATA Adli Tıp Anabilim Dalı Başkanlı̆̆l, Ankara \\ ${ }^{2}$ Adli Tıp Kurumu Ankara Grup Başkanlığı, Ankara \\ ${ }^{3}$ GATA Haydarpaşa Ĕ̈itim Hastanesi, Genel Cerrahi Servisi, İstanbul \\ ${ }^{4}$ Ankara Numune Hastanesi, 1. Radyoloji Kliniği, Ankara \\ ${ }^{5}$ Forensic Science Program, Alabama State University, Montgomery, USA.
}

\section{Özet}

Derin boyun enfeksiyonları, sıklıkla üst solunum yolu ve odontojenik enfeksiyonlara bağlı gelişebilirler. Gastrointestinal sistem perforasyonları ise birçok nedenle meydana gelebilir ve erken tanı ve acil cerrahi tedavi gerektiren durumlardır. Her iki durumda da geç veya yanlış tanı, artmış morbidite ve yüksek mortaliteye neden olabilir.

Diş apsesine bağlı derin boyun enfeksiyonu gelişen ve yatarak tedavi edilen bir olgunun "septik şok ve çoklu organ yetmezliği”" sonucunda hayatını kaybettiği bildirilmiştir. Otopside "retrofaringeal apse" tanısı doğrulanmış ve ilave olarak antemortem dönemde tanı almamış "duodenum perforasyonu" tespit edilmiştir. Otopside tıbbi uygulama hatasına ait bulgu tespit edildiğinde, bunun otopsi raporunda açıkça bildirilmesi gerektiğini düşünmekteyiz.

Anahtar Kelimeler: Diş apsesi; Retrofaringeal apse; Peptik ülser perforasyonu; Peritonit; Sepsis; Otopsi.

\section{Giriş}

Derin boyun enfeksiyonları; boyun potansiyel boşlukları ve kas fasiaları arasında meydana gelen apse veya selülit oluşumlarıdır. Her yaş grubunda görülebilen, tanıda güçlüklerle karşılaşılan ve komplikasyon oranı yüksek enfeksiyonlardır. Siklıkla üst solunum yolu ve odontojenik enfeksiyonlara bağlı gelişmektedir (1-3). Dental enfeksiyonlara bağlı gelişme oranının \%22.7-43 arasında olduğu bildirilmektedir (4). Nadir görülen bu enfeksiyonların çoğu, drenaj ve antibiyotik tedavisi ile tam olarak tedavi edilmelerine rağmen en ciddi komplikasyon mediastinit gelişmesidir (2). Geç tanı konulması durumunda mortalite oranının yüksek (\%40-50) olduğu bildirilmektedir (2-6).

Sorumlu Yazar: Doç.Dr. Sait Özsoy

GATA Adli Tıp AD. Başkanlığı, Ankara

E-posta:sozsoy@gata.edu.tr

Geliş: 20.03.2015 Düzeltme: 24.06.2015 Kabul: 29.06.2015

\section{Abstract}

Deep neck infection often develops due to upper respiratory tract and odontogenic infections. Gastrointestinal System perforation can occur for many reasons and is in need of early diagnosis and prompt surgical treatment. In both cases late or incorrect diagnosis may lead to increased morbidity and high mortality.

An inmate suffering from a deep neck infection which developed from a tooth abscess and resulted in multiple organ failure and septic shock died while being treated in a hospital. The autopsy confirmed "retropharyngeal abscess" and revealed in addition findings of duodenal perforation that was missed during clinical examination. According to Turkish Criminal Code, a finding of a misdiagnosis should not just be reported as the cause of death but clearly stated in the report.

Keywords: Dental focal infection; Retropharyngeal Abscess; Peptic Ulcer perforation; Peritonitis; Sepsis; Autopsy.
Akut karın; ani başlayan ve yedi günden daha az süren (çoğunlukla 48 saat), acil cerrahi girişim gerektirebilen, hastaların hemen her zaman karın ağrısı yakınması ile başvurduğu, batına ait bir patolojidir (7). Gastrointestinal sistem perforasyonları ise peptik ülser, enflamatuar hastalıklar, künt ya da penetre travma, iatrojenik sebepler, yabancı cisim veya tümör gibi birçok nedenlere bağlı meydana gelebilmekte ve erken tanı ile birlikte acil cerrahi tedavi gerektiren bir durumdur $(8,9)$. Aktif ülser hastalığ olanların \%5-10'unda perforasyon meydana gelebileceği ve en sik duodenal $(\% 60)$, antral $(\% 20)$ ve mide korpus (\%20) ülserlerinin perfore olduğu belirtilmektedir (10).

Diş apsesine bağlı derin boyun enfeksiyonu nedeniyle yatarak tedavi edilen bir olgunun "septik şok ve çoklu organ yetmezliğì" sonucunda hayatını kaybettiği bildirilmiştir. Otopside "derin servikal apse" yanında, antemortem dönemde tanı almamış "duodenum perforasyonu" da 
tespit edilen olgunun otopsi bulguları, nadir görülebilecek bir birliktelik olması nedeniyle ve ilave olarak da ilgili kliniklere geri bildirim amacıyla sunulmuştur.

\section{Olgu}

Hükümlü olarak bulunduğu hapishanenin sorumlu hekimi tarafindan ilaç tedavisi uygulanan 34 yaşındaki erkek olgu, tedavinin etkili olmaması nedeniyle sevk edilmiştir. Bir eğitim ve araştırma hastanesinde "diş apsesi sonrast gelişen derin boyun enfeksiyonu" tanısı ile kulak burun boğaz kliniğine yatırılmıştır. Kontrastlı bilgisayar11 tomografide (BT) solda ağız tabanı ve retrofaringeal alandan başlayıp, posterior parafaringeal alan ve boyun fasiyal planları arasında ilerleyen, sol juguler fossa düzeyinde, multiloküle hava-sıvı seviyeleri bulunan yaygın apse formasyonu tespit edilmiştir. Sol juguler venin tromboze olduğu, ancak hava pasajının açık olduğu saptanmıştır. Hastanın genel durumunun bozulması, üre kreatinin yüksekliği ve idrar çıkışı olmaması üzerine iç hastalıkları yoğun bakım ünitesine alınmıştır. Yoğun bakımda "septik şok ve çoklu organ yetmezliği" tanıları ile takip ve tedavi edilen hastada hipotansiyon, taşikardi, hipotermi geliştiği, hastanın dehidrate görünümde olduğu, bilincinin konfüze olduğu, kooperasyon bulunmadığı, hastaneye yatışının altınc1 gününde "akut böbrek yetmezliği, septisemi, septik şok, septisemi, asidoz, hiperkalemi, slvl-elektrolit ve asitbaz denge bozukluğu" nedeniyle öldüğü bildirilmiştir.

Olgunun hükümlü olması nedeniyle Minnesota protokolüne uygun şekilde yapılan otopsisinde; mandibula solunda molar diş ( 8 no.lu) ve çevre yumuşak dokuları içine alan $5 \times 2 \mathrm{~cm}$ 'lik bölgede apse tespit edilmiş ve apse içeriğinin ağız içine drene olduğu saptanmıştır (Resim 1). $\mathrm{Bu}$ apsenin, boyun solunda yüzeysel ve derin kas grupları arasinda ilerleyerek 10x6x5 cm'lik alanda servikofasiyal apse meydana getirdiği ve arka duvarından trakea lümenine fistülize olduğu tespit edilmiştir (Resim 2). Resüsitasyona bağlı ekimozsuz kosta kırıkları tespit edilmiştir. Akciğerlerin (sağ:610 gr, sol:545 gr) kesitlerinde iltihabi sekresyon aktığı saptanmıştır.

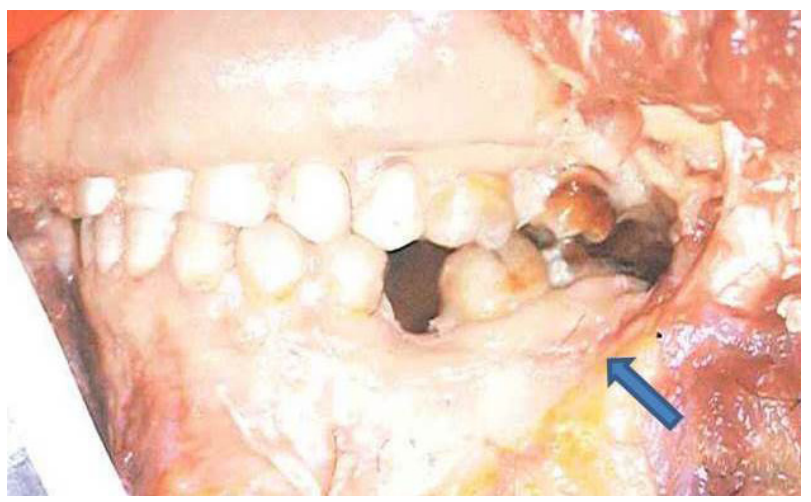

Resim 1. Mandibular diş kaynaklı apse oluşumu.

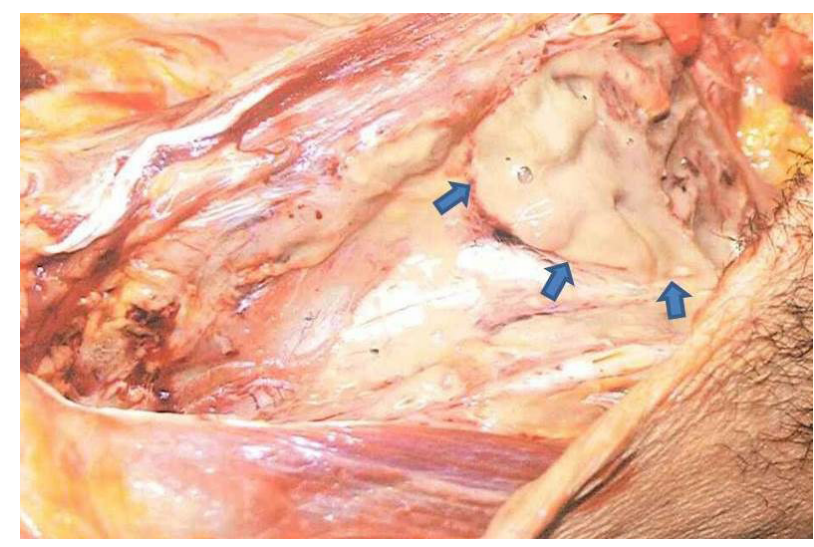

Resim 2. Derin boyun apsesi

Batın boşluğundan $4500 \mathrm{cc}$. sarı-yeşil-kahverenginde serbest mayii boşaltılmıştır. Duodenumda $2 \times 2 \mathrm{~cm}$ 'lik perforasyon tespit edilmiştir(Resim 3).

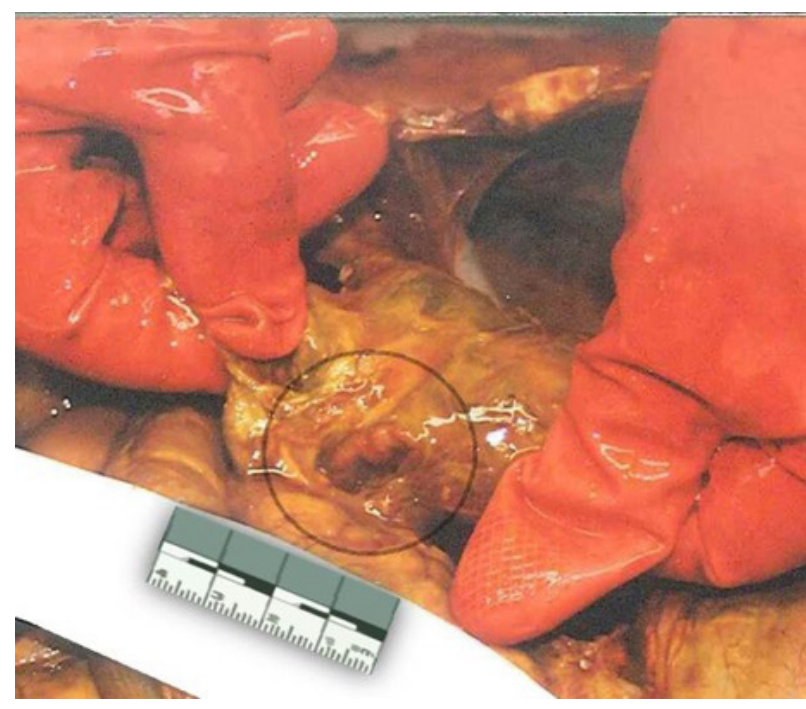

Resim 3. Duodenal perforasyon

Histopatolojik incelemede; boyun yumuşak dokularında granülasyon dokusu ve sialadenit bulguları, duodenumda perforasyon, peritonit, mezenter ve batın duvarında akut enflamasyon, karaciğerde yaygın nekroz alanları ve akciğerlerde bronkopnömoni bulguları tespit edilmiştir. Otopsi esnasında alınan kan, idrar, mide içeriği ve iç organ örneklerinde yapılan toksikolojik incelemede herhangi bir toksik madde saptanmadığ bildirilmiştir.

Kesin ölüm nedeninin "diş apsesi sonucu derin boyun enfeksiyonuna bağlı yaygın organ iltihabı, bu iltihaba bağlı duodenum perforasyonu, peritonit ve septisemi" olarak rapor edildiği belirlenmiş̧tir. 


\section{Tartışma}

Derin boyun enfeksiyonları en s1k mandibular odontojenik enfeksiyonlara sekonder olarak geliştiği bildirilmiştir (11). Yaşamsal tehlike oluşturan komplikasyonlara neden olabilmektedir $(4,6)$. Geç veya yanlış tanı konulmas1 durumunda morbidite ve mortalite (\%40-50) oran1$\mathrm{n} 1$ arttırabilmektedir (5). Bizim olgumuzda mandibular molar diş apsesinin ilerleyerek derin servikofasiyal apse oluşturduğu ve trakeada fistülize olduğu saptanmıştır. Hastanın ilk olarak ne zaman diş apsesi tanısı aldığı hakkında bilgi elde edilememiştir.

Derin boyun enfeksiyonlarının tanısında fizik muayene ile birlikte boyun ultrasonografisi (US), kontrastl 1 bilgisayarlı tomografi (BT) ve manyetik rezonans görüntüleme (MRG) kullanılmaktadır $(3,11,12)$. Tedavi edildiği süreçte hastaya yapılmış BT'de; ağız tabanı, retrofaringeal alan ve boyun fasiyal planları arasında yaygın apse formasyonu tespit edilmiştir. İlave olarak sol juguler venin tromboze olduğu da belirtilmektedir. Olgunun hastanede kaldığı süre içerisinde derin boyun enfeksiyonuna ve sonrasında gelişen komplikasyonlarına yönelik tedavilerin yapıldığ 1 görülmüştür. Ancak otopside tespit edilen duodenum perforasyonu ile ilgili herhangi bir muayene bulgusu, tetkik ya da ön tanının bulunmadığı anlaş1maktadır.

Akut epigastrik ağrısı ve abdominal rijiditesi olan hastalarda gastroduodenal perforasyon tanısının konulması zor değildir (13). Ancak yine de ayırıcı tanıda \%40'a varan yanlışlıkların görülebildiği bildirilmiştir (14). Peptik ülser perforasyonu peritonit ve ölüme neden olabilmekte, erken tanı ve uygun tedavi ile ölümler engellenebilmektedir. Bazı durumlarda ise peritonit tanısının otopsi sonrasında konulabildiği bildirilmiştir (15).

Uygunsuz analjezik kullanımı, altta yatan primer patolojiyi baskılayarak ya da klinik bulguları değiştirerek tanı konulmasını engellemektedir. Ayrıca nöropsikiyatrik ve kardiyopulmoner hastalıklar veya eşlik eden ciddi enfeksiyon hastalıkları gibi durumlarda da akut karın tanısı konulmasında gecikme olabilmektedir $(16,17)$. Olgumuzda; batın içinde $4500 \mathrm{cc}$ safra içerikli serbest sıvının, duodenumda tespit edilen $2 \times 2 \mathrm{~cm}$ 'lik perforasyondan kaynaklandığı belirlenmiştir. Batın içerisinde serbest sıvı birikimini açıklayacak başka bir patoloji saptanmamıştır.

Perfore peptik ülserde perforasyon sonrasında birinci aşamada kimyasal peritonit/kontaminasyon oluşabilmekte ve 6-12 saat sonra bazı hastalarda ağrıda biraz azalma oluşabilmektedir. Bunun nedeninin peritoneal sıvıların, tahriş edici gastroduodenal sıvıyı dilüe etmesinden kaynaklanabileceği belirtilmiştir. İntra-abdominal enfeksiyonun perforasyondan 12-24 saat sonra geliştiği bildirilmektedir (7). Tedavinin etkin şekilde yapılması, ülser perforasyonunda prognozu belirleyen en önemli etken olarak görülmektedir (9). Otopsi sonrasında yapılan histopatolojik incelemede; peritonda, mezenterde ve diğer batın içi dokularda tespit edilen akut enflamasyon bulguları tespit edilmiştir. Bu bulgular perforasyon ve peritoneal sepsis oluşumunun akut bir olay olduğunu göstermektedir.

\section{Sonuç}

Derin boyun apsesi ve perfore duodenal ülser hastalıkları ayrı ayrı yaşamsal tehlike oluşturabilmelerine rağmen, zamanında tanı ve uygun tedavi ile iyileşmesi mümkün hastalıklardır. Hastanın hekime geç başvurması, hekime başvurmadan önce yanlış tedavilerin kullanılmış olması, hastanın herhangi bir nedenle kendisini ifade edemiyor olması veya hastada ikincil patolojilerin varlığında hekimin doğru tanı koyabilmesi zorlaşabilir. İlave olarak, kendi uzmanlık alanı ile ilgili vücut kısmına odaklanan hekimler diğer sistemlerle ilgili patolojileri atlayabilmektedir.

Nörolojik ve/veya psikiyatrik hastalar başta olmak üzere iletişim problemi bulunan hastalar ile uyuşturucu-uyarıcı madde etkisi altında olan veya tutuklu ya da hükümlü gibi şüpheyle yaklaşılan hasta gruplarında hekimlerin önyargısız ve sistematik değerlendirme yapması önem arz etmektedir. "Varsa söyler, varsa görürüm deme! Sorarsan söyler, bakarsan görürsün!” ilkesinin, hekimleri tıbbi uygulama hatası yapmaktan koruyacak önemli bir yol gösterici olduğu görüşündeyiz.

Türk Ceza Kanunu'nun 280. maddesi gereğince, otopside tespit edilen tıbbi uygulama hatalarına ait bulguların otopsi raporu sonucunda, sadece ölüm nedenleri arasında bahsedilmekle kalmayıp, açıkça bildirilmesi gerektiğini düşünmekteyiz.

$\mathrm{Bu}$ çalışma Adli Tip Kurumu Eğitim ve Bilimsel Araştırma Komisyonu'nun izni ile yapılmıştır.

\section{Kaynaklar}

1. Goldberg MH, Topazian RG. Odontogenic infections and deep fascial space infections of dental origin. In: Topazian RG, Goldberg MH, Hupp JR, editors. Oral and maxillofacial infections. 4th ed. Philadelphia: Saunders; 2002. p. 158-187

2. Suehara AB, Goncalves AJ, Alcadipani PA, Kavahato NK, Menezes MB. Deep Neck Infection- analysis of 80 cases. Rev Bras Otorrinolaringol 2008;74:253-259.

3. Çağlı S, Yüce İ, Güney E. Derin Boyun Enfeksiyonları: 50 vakanın sonuçları. Erciyes Tıp Dergisi. 2006;28:211-215.

4. Lee JK, Kim HD, Lim SC. Predisposing factors of complicated deep neck infection: An analysis of 158 cases. Yonsei Medical Journal. 2007;48(1):55-62

5. Fliss DM, Tovi F, Zirkin HJ. Necrotizing Soft-Tissue Infections of Dental Origin. J Oral Marillofac Surg. 1990;48:1104-1108. 
6. Peker E, Karaca İ.R. Odontojenik enfeksiyon kaynaklı fasiyal alan apseleri. GÜ Diş Hek Fak Dergisi. 2012;29(2):129-137

7. Bertleff M. J.O.E., Lange JF. Perforated Peptic Ulcer Disease: A Review of History and Treatment. Dig Surg. 2010;27:161-169

8. Coppolino FF, Gatta G, Di Grezia G, Reginelli A, Iacobellis F, Vallone G, et al. Gastrointestinal perforation: ultrasonographic diagnosis. Critical Ultrasound Journal. 2013; 5 (Suppl 1):S4

9. 9Svanes C. Trends in Perforated Peptic Ulcer: Incidence, Etiology, Treatment, and Prognosis. World J. Surg. 2000;24(3): 277-283.

10. 1Saber A. Perforated duodenal ulcer in high risk patients, peptic ulcer disease. In: Chai J, editor. Peptic Ulcer Disease. In Tech, Rijeka-Croatia, Shanghai-China; 2011. p. 271-284

11. Marioni G, Rinaldi R, Staffieri C, Marchese-Ragona R, Saia G, Stramare R, et al. Deep neck infection with dental origin: analysis of 85 consecutive cases (2000-2006). Acta OtoLaryngologica. 2008;128:201-206

12. 1Gorjón PS, Pérez PB, Martín ACM, Dios JCP, Alonso SE,
Cabanillas MIC. Deep neck infection: Review of 286 cases. Acta Otorrinolaringol Esp. 2012;63(1):31-41

13. Roberto G, Romanob S, Pintob A, Romano L. Gastroduodenal perforations: conventional plain film, US and CT findings in 166 consecutive patients. European journal of radiology. 2004;50:30-36.

14. Kalafat H. Akut Karın. İ.Ü. Cerrahpaşa Tıp Fakültesi Sürekli Tıp Eğitimi Etkinlikleri Acil Hekimlik Sempozyumu. 16 -17 Ekim 1997; İstanbul. p. 221-231

15. Cina SJ, Mims WW, Nichols CA, Conradi SE. From emergency room to morgue: deaths due to undiagnosed perforated peptic ulcers: report of four cases with review of the literature. Am J Forensic Med Patho. 1994;15(1):21-27.

16. Felix WR, Stahlgren LH. Death by undiagnosed perforated peptic ulcer: analysis of 31 cases. Annals of surgery. 1973;177(3):344

17. Arslan MM, Eren A, Çekin N. Akıl Hastalarında Önyargılar Nedeniyle Tanısı Geçirebilen Veya Atlanabilen Hastalıklar İki Olgu Sunumu. Bull Leg Med. 2008;13(3):120-123. doi: 10.17986/blm.2008133680 